\title{
"Para uma história da vacina no Brasil": um manuscrito inédito de Norberto e Macedo
}

\author{
"For a history of vaccination in Brazil": an unpublished \\ manuscript by Norberto and Macedo
}

Myriam Bahia Lopes

Professora adjunta da Escola de Arquitetura/Universidade Federal de Minas Gerais; presidente do Núcleo de História da Ciência e da Técnica

Rua Gonçalves Dias, 2611/502 Santo Agostinho

30140-092 Belo Horizonte - MG Brasil

mbahia@uaivip.com.br

Ronald Polito

Historiador e escritor
LOPES, Myriam Bahia; POLITO, Ronald. “Para uma história da vacina no Brasil": um manuscrito inédito de Norberto e Macedo. História, Ciências, Saúde-Manguinhos, Rio de Janeiro, v.14, n.2, p.595-605, abr.-jun. 2007.

O manuscrito "Para uma história da vacina no Brasil" foi encontrado nos arquivos do Instituto Histórico Geográfico Brasileiro (IHGB), entre outros textos da lavra de Joaquim Manoel de Macedo ali depositados. Escrito em parceria com Joaquim Norberto, em 1859, sua produção foi motivada por demanda do imperador ao Instituto. Apresenta as características de um texto de fundação: a argumentação visa estabelecer o verdadeiro introdutor da vacina antivariólica no Brasil e resolver a controvérsia existente entre os nomes do marquês de Barbacena e do cirurgião Francisco Mendes Ribeiro de Vasconcellos. Analisa os documentos que fundamentam as duas versões e consolidam o marco inaugural para a história da vacina em território brasileiro em 1808, o que passou a ser reconhecido oficialmente pelo IHGB.

PALAVRAS-CHAVE: historiografia; prevenção; varíola.

LOPES, Myriam Bahia; POLITO, Ronald. "For a history of vaccination in Brazil": an unpublished manuscript by Norberto and Macedo. História, Ciências, Saúde - Manguinhos, Rio de Janeiro, v.14, n.2, p.595-605, Apr.-June 2007.

The manuscript "Para uma história da vacina no Brasil" [For a history of vaccination in Brazill was unearthed in the archives of Instituto Histórico Geográfico Brasileiro (IHGB) along with other texts by Joaquim Manoel de Macedo. It was written in partnership with Joaquim Norberto in 1859 in response to a request by the Emperor to the institute. Its characteristics mark it out as a founding text: its arguments are designed to establish who really introduced the smallpox vaccine to Brazil and to resolve the controversy between the Marquis of Barbacena and a surgeon, Francisco Mendes Ribeiro de Vasconcellos. It analyzes the documents that provide the basis for both versions and consolidates the beginning of the history of vaccination in Brazilian territory in 1878, which was subsequently recognized by IHGB.

KEYWORDS: historiography; prevention; smallpox. 
$\mathrm{O}$ manuscrito "Por uma história da vacina no Brasil", assinado por Joaquim Norberto de Souza Silva e Joaquim Manuel de Macedo encontra-se depositado na sede do Instituto Histórico e Geográfico Brasileiro (IHGB), no Rio de Janeiro, e a localização no acervo é Lata 42 - Doc. 13. É um documento de 19 folhas medindo $27 \times 20 \mathrm{~cm}$, escritas somente na página da frente e numeradas no canto superior direito. $\mathrm{O}$ texto não possui título, ainda que a ficha do catálogo informe que se trata de um "Parecer sobre a introdução da vacina no Brasil". O manuscrito estampa duas caligrafias. Salvo melhor parecer, da página 1 à página 13 ele foi escrito por Joaquim Norberto. Do terço final da página 13 à página 18, por Macedo. Aúltima página volta a ser manuscrita por Norberto. É bom o seu estado de conservação, à exceção da penúltima página. Nela, o último parágrafo foi integralmente riscado. Em decorrência da oxidação dos riscos, ela se partiu, o que dificulta a leitura do trecho suprimido. No final da página 8 e início da seguinte, também foi suprimida uma frase, cuja decifração é bastante difícil, pois ela se encontra muito riscada. Igualmente, ao longo do texto, os autores eventualmente substituíram palavras ou expressões ou ainda eliminaram breves passagens, mas essas alterações não são significativas para merecerem constar em notas. No entanto, o último parágrafo da penúltima página e a frase final da página 8 e início da seguinte, já mencionados, bem como uma terceira ocorrência de palavras suprimidas, foram transcritos e comentados em notas de rodapé. Atualizamos a ortografia e a pontuação do texto e respeitamos a paragrafação original. Substituímos as palavras e trechos sublinhados pela fonte tipográfica em itálico. Mantivemos as abreviaturas por serem ainda hoje de uso corrente. Desdobramos, contudo, as iniciais das assinaturas de Norberto e Macedo no fim do manuscrito. Empregamos '[sic]' nos casos em que foi necessário assinalar problemas gramaticais constantes no texto.

Joaquim Manoel de Macedo, médico e escritor, nasceu em Itaboraí, no Rio de Janeiro, em 1820. Formou-se em medicina em 1844, quando defendeu a tese Considerações sobre a nostalgia. Exerceu por curto período a medicina no interior do Rio de Janeiro. Lecionou no Colégio Pedro II, foi diversas vezes deputado à Assembléia Provincial do Rio de Janeiro e à Assembléia Geral, membro do IHGB, do Conselho Diretor da Instrução Pública da Corte e do Partido Liberal, Cavaleiro da Ordem da Rosa, Comendador da Ordem de Cristo e Patrono da Cadeira número vinte da Academia Brasileira de Letras. Editou a revista A Guanabara, com Araújo Porto Alegre e Gonçalves Dias. Como prosador, destaca-se com A moreninha, O moço loiro e As vítimas-algozes; como poeta, escreveu "A nebulosa", poema importante do Romantismo brasileiro. Levou à cena a ópera $O$ primo da Califórnia, o drama Amor e pátria, as comédias Luxo e vaidade e A torre com concurso, entre outros. Escreveu sátiras romanceadas, 
como A luneta mágica e A carteira do meu tio. Publicou ainda os compêndios intitulado Lições de história do Brasil e Noções de corografia do Brasil. Como jornalista e editor, publicou o Ano bibliográfico brasileiro, entre 1876 e 1880.

Joaquim Norberto de Souza Silva, historiador e literato, nasceu em 1820 no Rio de Janeiro e faleceu a 14 de maio de 1891, na cidade de Niterói, também no estado do Rio de Janeiro. Escreveu cerca de oitenta obras sobre temas variados, de questões indígenas a aspectos demográficos do Brasil. Pertencente ao movimento romântico e na condição de crítico literário, dedicou-se à biografia de poetas árcades mineiros, tendo publicado Dirceu e Marília e Modulações poéticas, precedidos de um Bosquejo da história da poesia brasileira, em 1841. Como prosador destacou-se com Os assassinos misteriosos (1839) e As duas órfãs (1840). Escreveu para a Revista Popular, que circulou entre 1859 e 1862. No teatro escreveu a tragédia em verso Clitemnestra. Encontramos registro da encenação de apenas uma de suas peças teatrais, realizada em 1846, com João Caetano no papel principal de Amador Bueno ou a fidelidade paulistana. Organizou o Arquivo da Secretaria de Estado dos Negócios do Império, período em que pesquisou os manuscritos inéditos dos autos da devassa da Inconfidência, que deram origem ao seu livro História da Conjuração Mineira, no qual destaca o papel de Bárbara Heliodora e Maria Dorotéa na revolta de Vila Rica. Em 25 de outubro de 1850, na 220ª sessão do Instituto Histórico e Geográfico Brasileiro indicou Beatriz Francisca de Assis Brandão para ocupar o lugar de sócia do Instituto (cf. Revista do Institu to Histórico e Geográfico Brasileiro, Rio de Janeiro, 1850, tomo 13, p.530-531), instituição que presidiria entre 1886 e 1891. A indicação foi preterida pelos colegas Joaquim Manoel de Macedo e Gonçalves Dias, sob o pretexto de que Beatriz não se sentiria à vontade em uma instituição masculina. 


\section{Para uma história da vacina no Brasil}

À Comissão Subsidiária de Trabalhos Históricos foi presente o ofício do senhor ministro e secretário dos Negócios do Império remetendo de ordem de S. M. o Imperador o requerimento em que a exma. senhora viscondessa de Santo Amaro diz ter sido seu falecido pai o marquês de Barbacena quem introduziu a vacina no Brasil no ano de 1804, e pede licença para colocar na sala do Instituto Vacínico desta Corte o busto em mármore do mesmo marquês, para que assim se perpetue a sua memória e reconheça a posteridade a quem deve o benefício de tão grande bem introduzido no país, a fim de que o Instituto Histórico informe com o que se lhe oferecer, bem como o ofício do senhor Antônio Mendes Ribeiro acompanhando alguns documentos com que pretende mostrar que seu falecido pai o cirurgião-mor Francisco Mendes Ribeiro de Vasconcelos já havia introduzido tal benefício no Rio de Janeiro no ano de 1798.

A Comissão não satisfeita com estudar e avaliar os documentos que lhe foram remetidos, recorreu ao testemunho da história, que lhe foi inteiramente muda a esse respeito, como também aos documentos existentes no arquivo da Secretaria do Império e que de muito lhe serviram.

A propagação da vacina só foi introduzida em nossa pátria muitos anos depois da descoberta que imortalizou o gênio de Eduardo Jenner, e entretanto ninguém ignora os horrores de que foram teatro as plagas brasileiras assoladas pela epidemia das bexigas. São negras as páginas da história que nos relatam essa terrível calamidade importada pelos conquistadores no Novo Mundo, e o grito de pavor, o grito de "Merebahyba", como se se dissesse "as chagas más", que levantaram todas as tribos, foi o sinal para a sua dispersão; os índios desamparavam as suas aldeias e fugiam espavoridos, e, contaminados do mal, levavam por toda a parte a desolação e a morte, e deixavam os lugares de sua passagem juncados de cadáveres. Era crença entre eles que esse mal lhes era transmitido pelos padres jesuítas com a água do batismo, e assim recusavam submeter-se com seus filhos a esse sacramento, o que impediu não poucas vezes a conversão das almas. Não se sabe se essa crença lhes foi infundida pelos portugueses contrariados em seus sonhos de ambição pelos jesuítas, defensores estrênuos dos índios, ou se lhes foi inspirada pelos seus pajés, feridos no seu amor-próprio pela veneração que votavam as tribos aos padres jesuítas. Desgraçadamente os conquistadores, que se apresentavam de espada em punho, procuraram tirar partido do pavor que inspirava tão horrível epidemia para assolar as tribos que lhes eram contrárias e despovoar as suas aldeias; foi pois também propagado como um meio de guerra!

O historiador Rocha Pita refere com brilhante e poético estilo os estragos que fizeram as bexigas, e depois a fome, nas capitanias ao sul e ao norte da Bahia, no ano de 1666, males que a sua imaginação fantástica atribui à aparição do magnífico cometa que encheu o céu de sua imensa cauda e que infundiu pavor aos povos de então.

O governo português não foi indiferente aos males que sofria a sua colônia brasileira, mas também as suas medidas de prevenção, tomadas sem método algum, ou repousando apenas em recomendações, foram infrutíferas; assim, nas longas instruções que o príncipe regente dirigiu em 1803 ao conde dos Arcos, governador e capitão-general da capitania do Pará e que existem na Secretaria do Império, apenas se encontram estas palavras: "Introduzir a inoculação das bexigas, das quais são vítimas tantos mil braços que fazem tão sensível falta às culturas e aos trabalhos que a elas se seguem". 
Só no ano de 1805 é que se tomaram medidas eficazes; pelo menos tem essa data o primeiro documento oficial que aparece sobre a inoculação da vacina. É a portaria de 11 de fevereiro, pela qual ordenou o vice-rei o marquês de Aguiar que na casa da Câmara Municipal, hoje Câmara dos Deputados, tivessem lugar esses trabalhos, dando a sua inspeção ao coronel Manuel dos Santos de Carvalho, encarregado da polícia da cidade, depois substituído pelo marechal Miguel Nunes Vidigal, tendo por operadores dois cirurgiões ajudantes, e por escriturário um sargento do $2^{\underline{0}}$ regimento de linha.

Com a chegada da família real em 1808 decaíram os trabalhos de vacinação, por isso que a casa do senado da Câmara passou a ser ocupada pelos augustos hóspedes e a vacina teve de refugiar-se numa botica fronteira à mesma casa; era porém o local mal escolhido pela sua pequenez e impropriedade, e os vacinadores começaram a descuidar-se de sua missão, não obstante a inspeção do doutor Teodoro Ferreira de Aguiar, comissionado pelo governo. O conde de Linhares, então ministro de Estado dos Negócios do Reino, mandou removê-la em janeiro de 1811 para a casa do intendente geral da polícia Paulo Fernandes Viana, de acordo com o físico-mor do reino, a fim de darem-lhe forma regular. A longitude da casa do intendente atraía pouca concorrência, e em fevereiro tornou-se a removê-la para a casa do senado da Câmara, onde conservou-se.

Finalmente, em 4 de abril de 1811, baixou o alvará da organização do estabelecimento permanente para com mais extensão e regularidade se propagar e se conservar em beneficio dos povos o reconhecido preservativo da vacina, debaixo das vistas do intendente geral da polícia e do físico-mor do reino, arbitrando-se gratificações proporcionadas às pessoas nomeadas para os diversos empregos que se criaram.

Eis o que se desprende de documentos oficiais: quem foi, porém o introdutor da vacina no Brasil? Seria o marechal do exército Felisberto Caldeira Brant, depois marquês de Barbacena, a datar de 30 de dezembro de 1804, ou o cirurgião-mor Francisco Mendes Ribeiro de Vasconcelos antes de 15 de junho de 1798 ? É o que cumpre examinar.

No requerimento que a exma. senhora viscondessa de Santo Amaro dirigiu a S. M. o Imperador, alega que foi seu falecido pai, o marquês de Barbacena, quem introduziu a vacina no país, conseguindo realizar o seu intento em 30 de dezembro de 1804. Esta alegação baseia-se em documentos; estes documentos são 5 cartas, em pública forma, extraídas do livro da correspondência do nobre marquês.

É a $1^{a}$ carta datada da Bahia a 8 de agosto de 1804, dirigida ao cirurgião-mor Teodoro Ferreira de Aguiar, que então propagava a vacina em Lisboa com feliz sucesso, como soubera do doutor Avelino; a ele pediu o nobre marquês valioso auxílio para sua introdução no Brasil. Tinha lido que os espanhóis trouxeram a vacina às suas colônias americanas embarcando 20 meninos para se vacinarem durante a viagem a fim de chegar por esse modo a matéria ainda fresca e produzir o desejado efeito, e tomara o mesmo expediente. O navio portador da carta, Bom Despacho, levou também sete crias que ainda não tinham tido bexigas, as quais julgou bastante, visto que a extração do pus se costumava a fazer, como ainda hoje se faz, ao oitavo dia, e a viagem não levava então mais do que quarenta ou cinqüenta dias. As sete crias foram confiadas ao cuidado do cirurgião do mesmo navio, Manuel Moreira da Rosa, homem hábil e consumado prático.

A $2^{a}$ carta, com a mesma data, dirigida ao cirurgião do navio Bom Despacho, acima mencionado, teve por fim reiterar as recomendações verbais que lhe fizera com a intenção de evitar esquecimento em matéria tão importante. Recomendava-lhe a entrega da $1^{\text {a }}$ carta ao cirurgião-mor Teodoro Ferreira de Aguiar, encarregado de vacinar uma das sete 
crias em sua presença, sete dias antes da saída do navio, para que se tivesse toda a certeza de sua eficácia. Recomendava-lhe mais que lhe trouxesse alguns enjeitados e aproveitasse as pessoas da tripulação não vacinadas, receoso de que a viagem se prolongasse por qualquer contratempo; que conservasse o pus da mesma maneira que os ingleses o conservavam para remetê-lo para Lisboa, tomando informação a respeito e, para realização dessa grande idéia toda patriótica e humanitária, pôs à sua disposição os meios pecuniários, deixando aberta a sua bolsa, ou antes o seu crédito.

A $3^{a}$ carta é dirigida a seu genro (?) Amaro Velho da Silva, então residente nesta Corte, e datada da Bahia a 14 de março de 1805. Teve por portador ao cirurgião ajudante de seu regimento, que vinha munido de uma remessa de pus vacínico. "Pode vmcês., dizia o ilustre marquês, e todos os seus aproveitarem-se dele, que vacina com muita perfeição. Aqui o número dos vacinados já excede a três mil e nunca me pareceu que pudesse em minha vida e com minhas fracas forças fazer tão grande benefício à humanidade como foi introduzir a vacina na Bahia. O nosso governador quis ser quinhoeiro desta glória e por isso vai adiantando a introdução nos outros pontos do Brasil. Agora manda para o Rio, e fica outra expedição para Pernambuco."

A $4^{a}$ carta é dirigida a José Pinheiro Salgado e datada da Bahia a 16 de março de 1805. Depois de algumas notícias de interesse privado diz o marquês: "Finalmente consegui introduzir a vacina neste país... Já se não fala aqui em bexigas; o número de vacinados já excede o 3.000 e hoje vai a matéria para o Rio, e brevemente para Pernambuco pelo mesmo método que mandei vir de Lisboa, isto é, com moleques embarcados para se vacinarem durante a viagem."

A $5^{\mathrm{a}}$ carta é dirigida a José Joaquim Jorge e datada da Bahia a 5 de julho de 1805 . Achase nela o seguinte trecho: "Emprestei ao cirurgião Moreira $180 \$$ réis para ele poder fazer a esse país o grande presente da vacina, de cuja quantia saco a letra inclusa a pagar a vmcês."

Remetido a requerimento da ilustre suplicante ao Instituto Vacínico desta Corte pela Secretaria de Estado dos Negócios do Império, deu o seu inspetor geral o sr. dr. Jacinto Rodrigues Pereira Reis a seguinte informação: "Não veio ainda ao meu conhecimento, nem existe no arquivo do Instituto Vacínico nesta Corte documento algum oficial que confirme ou destrua tais alegações, e apenas possuo um folheto do falecido inspetor desta instituição Hércules Otaviano Muzzi, publicado na Tipografia Nacional em 1838, sob o título de Compêndio sobre a vacina, em que, tratando a página 6 da época em que apareceu este preservativo no Rio de Janeiro, assim se exprime: 'Em 1804 o governo de Portugal mandou a vacina para a Bahia a instâncias do exmo. marechal Felisberto Caldeira Brant, hoje marquês de Barbacena, que a expensas suas mandou a Lisboa alguns escravos e juntamente um facultativo, a fim de que, transmitindo-a de braço a braço, chegassem à Bahia com toda a sua energia; a direção deste trabalho foi então confiada ao doutor José Avelino Barbosa.

Em outubro do mesmo ano chegou pela primeira vez a esta cidade, vindo um cirurgião militar vacinando a indígenas e pretos escravos do mesmo marquês por toda a viagem, e chegou em perfeito estado. O marquês de Aguiar, então vice-rei, ordenou aos médicos, cirurgiões-mores, e ajudantes da guarnição da praça comparecessem no palácio do governo e aí principiando a vacinar nas quintas feiras e domingos...' (Daqui por diante fala somente na propagação da vacina nesta Corte.)

Este trecho do folheto de Muzzi, conquanto não guarde um perfeito acordo com as alegações do requerimento e com as cartas a este anexas, pois que refere que em outubro 
do mesmo ano (1804) chegara a vacina a esta cidade, quando no requerimento se alega ter ela chegado à Bahia em 30 de dezembro, e na $3^{\text {a }}$ carta, que é de 14 de março de 1805 , se diz que era nessa data enviada pela primeira vez para esta Corte, mantém todavia a integridade do fato fundamental, e nele não revelando a fonte donde emanavam as informações que contém, não pode ser aquilatada [sic] como de um valor histórico mais importante do que a dos documentos exibidos pela suplicante, deve-se apesar disso ter muito em conta que foi escrito por um contemporâneo, o qual era já nessa época cirurgião militar e como tal não seria indiferente ao conhecimento de um fato tão notável como devera ser o benefício da vacina trazida para o Brasil."

As informações que deu o sr. dr. Neto Machado, $2^{\circ}$ oficial servindo de chefe da $5^{\mathrm{a}}$ seção da Secretaria de Estado do Império, cifram-se nestas palavras: "Não me julgo habilitado para emitir um parecer sobre esta matéria por falta de documentos oficiais, entretanto me parece que devem ser tomadas em consideração as cartas que a viscondessa de Santo Amaro juntou ao requerimento."

Os documentos de que trata o oficio do senhor Antônio Mendes Ribeiro são os seguintes:

$1^{\text {o }}$ Atestado de 34 pessoas residentes nesta Corte, datado de 15 de junho de 1798. ${ }^{1}$ Por este atestado se vê que o cirurgião-mor do $1^{\circ}$ Regimento de Infanteria das antigas milícias desta Corte, Francisco Mendes Ribeiro de Vasconcelos, viajou por alguns dos reinos de Inglaterra, França, Itália, Espanha e Portugal onde vira a inoculação das bexigas e do [sic] grande acerto com que os professores desempenhavam a sua aplicação: "E por ter chegado, dizem os signatários do atestado, à nossa notícia que Francisco Mendes Ribeiro de Vasconcelos, cirurgião-mor do $1^{\circ}$ Regimento de Infantaria de Milícias da capital do Rio de Janeiro, de que é coronel o ilustríssimo e excelentíssimo conde vice-rei do Estado, tem trilhado alguns dos reinos acima ditos e muitas pessoas fidedignas nos fazem saber que este mesmo professor nas partes do sul pôs em prática a dita inoculação em número avultado de pessoas de diferentes idades, gozando estes da felicidade de escaparem todos e ficarem isentos de defeitos e aleijões que causam as bexigas naturais pelo grande rigor com que atacam as criaturas; conhecidas por nós todas estas vantagens, lhe conferimos os nossos filhos escravos e domésticos (como melhor se vê da relação junta) para neles pôr em prática a dita inoculação, o que logo deu princípio o dito cirurgião-mor em junho do presente ano, e passamos todos pela satisfação de vermos os ditos nossos filhos e domésticos atacados das mais formosas e discretas bexigas, correndo estas todo o seu curso sem perigo, nem turbar-lhes [sic] as suas inocentes diversões, livre [sic] de sintomas, fora da cama, e fazendo passeios fora de casa; não embaraçando a toda esta felicidade a crítica estação que se experimenta neste país nos meses de junho e julho. Esta útil e proveitosa inoculação se deve ao nosso parecer estender-se ao restante desta América, assim como está introduzida em quase toda a Europa para benefício do público e aumento do Estado, sendo este o único meio por onde se pode livrar as criaturas do cruel açoite que experimentam nesta cidade, do grande número dos estropiados causado pelas bexigas naturais, de muito maior aumento nas lavouras dos senhores de engenho e outras fábricas." 
2 ํㅡㄹ Atestado de 33 pessoas também residentes nesta Corte, datado de 20 de fevereiro de 1800, que asseveram que o mesmo cirugião-mor aplicou a inoculação das bexigas em seus escravos e domésticos com feliz sucesso.

$3^{\text {o }}$ Atestado do Senado da Câmara desta cidade datado de 8 de junho de 1803. Diz ele que o mesmo cirurgião-mor merecera geral aplauso e igual aceitação do público em exercitar peritamente a inoculação das bexigas, que a praticava em infinitas pessoas com satisfação dos espectadores e felicidade dos inoculados, que todos adquiriam a desejada saúde, pelo que se conhecia ser o mesmo cirurgião insigne em sua profissão e se fazer digno de qualquer graça que S. A. Real lhe quisesse fazer.

$4^{\circ}$ Atestado de Antônio Corrêa da Costa, coronel chefe do $1^{\circ}$ Regimento de Infanteria das antigas milícias desta Corte, datado de 15 de outubro de 1809. Certifica que o mesmo cirurgião-mor estava sempre pronto para desempenhar as funções de seu ministério e que ao mesmo tempo se desvelava na inoculação da vacina aplicada aos soldados do regimento, na conformidade da real ordem dirigida em 24 de maio de 1808 pela Secretaria de Estado de Negócios Estrangeiros e da Guerra.

Comparando as datas destes documentos apresentados pelos descendentes do marquês de Barbacena e do cirurgião-mor Francisco Mendes Ribeiro de Vasconcelos, a comissão não hesitaria em colocar este último em primeiro lugar; mas como? Como introdutor da vacina ou como introdutor da inoculação das bexigas? É o que cumpre ainda examinar, pois além da precedência cronológica existem duas questões a tratar, a inoculação das bexigas e a vacina.

Sabe-se geralmente o que se praticava antes da descoberta da vacina. Conhecida desde tempo imemorial tanto na África como na Ásia, introduzida em Constantinopla no ano de 1673, importada por lady Wortley Montagu na Inglaterra no século passado, o uso da inoculação das bexigas se derramou por toda a Europa com o fim de neutralizar os funestos efeitos desta terrível epidemia. Era fácil a operação, que consistia unicamente em introduzir na epiderme o vírus de uma pústula variólica no perfeito estado de sua madureza; tinha, porém, seus inconvenientes, e com a introdução da vacina foi sendo proscrita e hoje já ninguém fala nela.

Ora, nos documentos que temos à vista acham-se discriminadas de um modo satisfatório as duas inoculações. "Desde que soube desta feliz descoberta, diz o marquês de Barbacena falando da vacina na sua $1^{\mathrm{a}}$ carta, mandei pedir a matéria a Picanço; que respondeu ao meu amigo Salgado me aconselhasse a inoculação das bexigas naturais, porque a vacina não chegaria cá em estado de produzir efeito, e na verdade assim tem acontecido com a que vmcê. mandou ao doutor Avelino. Foi meu filho vacinado e muitas outras crianças, porém debalde, o que nos deixou em grande desgosto por nos parecer seria perdido para esta grande parte do mundo tamanho bem." Nos documentos que apresenta o sr. Antônio Mendes Ribeiro trata-se sempre, com exceção de uma única vez, da inoculação das bexigas. A única vez que se trata da inoculação da vacina é no documento que tem a data de 15 de outubro de 1809, quando a vacina já era conhecida no Brasil pelos esforços do marquês de Barbacena, e vê-se mesmo que o cirurgião-mor Francisco Mendes Ribeiro de Vasconcelos não a praticava de modus próprio, mas sim em confor- 
midade da real ordem dirigida em 24 de maio de 1808 pela Secretaria de Estado dos Negócios Estrangeiros e da Guerra, segundo as expressões do coronel do seu regimento. Acresce ainda uma razão e é que esses documentos foram obtidos na intenção de pedir uma graça ao governo de S. A. Real, como se depreende do atestado do senado da Câmara, e não consta dos livros da Secretaria do Império que o príncipe regente, que recomendava ao conde dos Arcos a inoculação das bexigas, recompensasse os esforços do suplicante, sem dúvida porque naquela secretaria se tinha notícia do serviço prestado pelo marquês de Barbacena.

Pondo pois de parte os documentos que à consideração do Instituto Histórico ofereceu o senhor Antônio Mendes Ribeiro, graças à publicidade introduzida em nossos trabalhos, resta à comissão algumas reflexões acerca da validade dos documentos do requerimento da exma. senhora viscondessa de Santo Amaro, da falta de documentos oficiais lamentada pelos senhores doutores Reis e Neto Machado.

A introdução da vacina no império é um fato; mais de meio século se tem passado sem que alguém haja reclamado a glória dessa introdução que de tanta utilidade tem sido ao país, e nem consta de documento algum oficial que ao governo se deva esse benefício; neste ponto a comissão limita-se à transcrição das seguintes considerações do sr. dr. Jacinto Rodrigues Pereira Reis: "Sendo, porém, ainda muito para notar-se que não tendo o trecho que acima transcrevo (fala da memória de Muzzi), e que circulou impressa com toda a publicidade, suscitado reclamação alguma, pode-se inferir sem repugnância que as cartas escritas pelo falecido marquês de Barbacena em 1804 e 1805 a respeito deste objeto não podiam ser ditadas pela impostura ou por um cálculo por demais previdente, a que não precisava ele recorrer para granjear tantos títulos gloriosos, que ilustram o seu nome."

A falta de documentos oficiais deplorada pelos srs. doutores Reis e Neto Machado não é felizmente real, mas esses documentos só apareceram depois de suas louváveis pesquisas entre os papéis perdidos na classificação confusa do arquivo velho da Secretaria do Império.

Além de outros, existem dous documentos relativos à introdução da vacina. O primeiro tem por título História da introdução e propagação da vacina no Brasil e traz a assinatura de Hércules Otaviano Muzzi, e teve por fim apresentar algumas lembranças para um plano geral de vacina no império. Notam-se estas palavras na parte histórica: “Em 1804 veio a vacina pela primeira vez ao Brasil mandada pelo governo de Portugal, cooperando para isso o exmo. marquês de Barbacena, que enviou escravos seus a Lisboa para virem-na reproduzindo de braço a braço, e chegar à Bahia em todo o seu vigor e energia, dandose a direção deste trabalho ao doutor José Avelino Barbosa. O governador da Bahia, segundo as ordens que tinha recebido de Portugal, mandou para esta Corte, vindo um cirurgião militar vacinando índios em toda a viagem até que chegou a esta Corte em dias de outubro do mesmo ano.

O marquês de Aguiar, então vice-rei, ordenou aos médicos, cirurgiões-mores e ajudantes da guarnição desta capital, que comparecessem todos no palácio do governo e deu-se princípio à vacinação a que o mesmo vice-rei assistia, designando as $5^{\text {as }}$ feiras e domingos, o que se tem seguido até hoje. Este salutar benefício foi logo recebido pelo povo, apesar dos declamadores contra ele, por isso que viram melhorada a sorte das crianças, grassando as bexigas nos meses de outubro, novembro e dezembro, como era costume, observavam que as vacinadas subtraíam-se ao contágio." 
O segundo documento é a Exposição da introdução da vacina no Brasil, seu estado atual nesta Corte e de algumas reformas para o seu melhoramento, que a junta vacínica tem a honra de apresentar ao ilmo. e exmo. sr. conselheiro José Clemente Pereira. Tem a data de 12 de janeiro de 1828 e está assinada por Antônio José da Lança, Hércules Otaviano Muzzi, Florêncio Antônio Barreto, José Joaquim de Lima Pestrano, membros da instituição vacínica, e pelo escrivão da junta João Ribeiro da Silva Guimarães. Os seguintes trechos são da exposição histórica:

"Havia já muito tempo que a Europa desfrutava os benefícios da vacina e arrancava à morte milhares de inocentes, condenados a ser vítimas do terrível flagelo das bexigas, e o governo de Portugal nunca se lembrara de transmitir ao Brasil a mais útil das descobertas humanas, quando aliás nenhum país mais do que ele carecia deste salutar invento ou se atendesse às vantagens da população ou ao perdimento de imensas somas na mortandade contínua de escravos, que este flagelo devorava. O certo é que mais ocupado de seu ouro que de seus habitantes, Portugal, como em outros muitos casos, esperou que o Brasil por seu próprio impulso remediasse a este mal. Foi preciso que alguns negociantes da Bahia, aterrados com a horrorosa ceifa de vidas que este contágio anualmente fazia na sua província, e dirigidos por uma filantropia que infinitamente os honra, mandassem à sua custa buscar a Portugal o pus vacínico, enviando alguns meninos para o transportar e o senhor doutor José Avelino Barbosa para examinar e observar o método prático de sua operação. A Providência abençoou os esforços generosos destes honrados brasileiros, e a Bahia, tendo a honra de ser o berço da instituição vacínica no Brasil, teve a boa fortuna de a ver prosperar rapidamente e de achar nesta prosperidade a base principal do aumento da sua população.

A estes mesmos homens, a estes verdadeiros amigos da mocidade baiana deve o Rio de Janeiro o estabelecimento vacínico. Não contentes de ter comunicado à Bahia tão feliz descoberta, transmitiram-na também a esta Corte, mandando ao mesmo tempo um facultativo para ensinar o método prático de sua operação.

Governava então esta cidade dom Fernando José de Portugal, depois marquês de Aguiar; e cumpre confessar que este homem ilustrado recebeu com devido apreço o presente que ao Rio de Janeiro enviava a Bahia, e que nem um esforço poupou para que ele igualmente aqui prosperasse. Chamou à sua residência os práticos do país e na sua mesma presença mandou fazer as primeiras operações e depois encarregou ao capitão Manuel dos Santos de Carvalho o cuidado deste assunto, a quem sucedeu o capitão Miguel Nunes Vidigal, nomeando igualmente os facultativos que deviam ocupar-se de seu desempenho. Continuou-se com pequenas alterações e com grande vantagem pública até que o alvará de 4 de abril de 1811 criou a Instituição Vacínica, debaixo da direção do físico-mor do Reino e do intendente geral da polícia. Foram por essa ocasião nomeados um inspetor, um escrivão e três cirurgiões, aquele com $400 \$ 000$ réis de ordenado e o segundo, bem como os últimos com 200\$000 réis; o número dos cirurgiões foi depois aumentado e hoje existem cinco.

Velho costume foi sempre no nosso passado governo, quando organizava qualquer nova criação, dar-lhe logo um apanágio extraordinário, fosse ou não fosse consentâneo com o objeto e exigido por sua natureza; e depois queria resgatar à custa de pequenos ordenados, o que melhor fazia ocupando menos empregados. Esta a razão por que vemos nesta criação um inspetor que de nada serviu e um diretor, o físico-mor, que pouco ou nada fez pelo estabelecimento, e vemos a módica quantia ou antes insignificante aplicada aos membros ativos sobre quem recai o trabalho." 
Esses documentos estão de acordo com as cartas do marquês de Barbacena, embora neste último não se faça menção de seu nome, e no $1^{\circ}$ haja um engano de datas. ${ }^{2}$

É pois a comissão de parecer: $1^{\circ}$ que se devolva ao senhor ministro do Império o requerimento da exma. senhora viscondessa de Santo Amaro e se diga que os documentos que apresenta estão de acordo com os documentos oficiais existentes no arquivo da própria Secretaria do Império, e que a comissão examinou cuidadosamente; $2^{\circ}$ que sejam entregues ao senhor Antônio Mendes Ribeiro os documentos que ofereceu à consideração do Instituto fazendo-se-lhe ver que o que seu pai praticava nesta Corte desde o ano de 1798 não era mais do que a inoculação das bexigas, que difere da da vacina, a qual também praticara, mas depois da sua introdução pelo marquês de Barbacena, e em virtude da Ordem Real de 24 de maio de 1808, como se depreende de seus próprios documentos.

Alongando-se em demasia em suas considerações e apresentando os trechos dos documentos que lhe foram presentes, a comissão teve em vista, além do exame que lhe foi cometido, reunir em seu parecer todos os apontamentos que podem servir à história da vacina no Império.

Sala das sessões do Instituto Histórico, em 23 de setembro de 1859.

Joaquim Norberto de Souza Silva Joaquim Manuel de Macedo ${ }^{3}$

\section{NOTAS}

${ }^{1}$ A continuação desta frase, no final da página 8 e início da seguinte do manuscrito, foi riscada. Apresentamos aqui sua transcrição (deixamos entre colchetes as palavras de mais difícil decifração): "sendo que os algarismos que designam [os anos] acham-se sublinhados e repassados de tinta mais preta a fazer crer que houve alteração".

2 Após esse parágrafo, há um longo parágrafo que foi suprimido do texto final, pois se encontra riscado. Sua transcrição não é simples, não apenas pelos riscos que dificultam a decifração do texto, como pelas emendas que sofreu no processo de sua redação, até a decisão dos autores de suprimi-lo na íntegra. Numa primeira redação era este o seu conteúdo (entre colchetes, as passagens de mais difícil decifração): “Quanto à pretensão da ilustre peticionária, parece à comissão não só justa como digna de elogios, e [nem] é uma inovação entre nós. Não ordenou a Assembléia Legislativa da Bahia a colocação do busto do visconde de Cairú numa das salas da biblioteca pública de sua capital? Não se consentiu que o retrato de Tomás Antônio de Vila Nova Portugal, que como ministro do Reino instituiu o Museu Nacional, figurasse em uma das salas do mesmo museu? O marquês de Barbacena, além da introdução da vacina, introduziu o vapor entre nós, não só nos engenhos de açúcar como na navegação, e é digno ainda por outros muitos títulos da estima de seus concidadãos". Após as emendas e os trechos suprimidos, esta seria a redação definitiva do parágrafo: "Quanto à pretensão da ilustre peticionária, não é ela uma inovação entre nós. Não se consentiu que um parente pudesse colocar [em] uma das salas do Museu Nacional desta Corte o retrato de Tomás Antônio de Vila Nova Portugal, que como ministro do Reino instituiu o mesmo Museu Nacional, sem citar outros muitos exemplos? O marquês de Barbacena, além da introdução da vacina, introduziu o vapor entre nós, não só nos engenhos de açúcar como na navegação".

3 Após a assinatura, Macedo colocou um travessão e duas palavras, que posteriormente foram riscadas. Sua leitura é bastante difícil em decorrência da oxidação (o papel se partiu). Ao que parece, está escrito: "com restrições". 